\title{
Molecular characterization of a novel mycovirus in the cultivated mushroom, Lentinula edodes
}

\author{
Yumi Magae
}

\begin{abstract}
Background: In the 1970s, mycoviruses were identified that infected the edible mushroom Lentinula edodes (shiitake), but they were not regarded as causal agents for mushroom diseases. None of their genes has been sequenced. In this study, the dsRNA genome of a mycovirus recently found in a shiitake commercial strain was sequenced and its molecular structure was characterized.
\end{abstract}

Methods: A cDNA library was constructed from a dsRNA purified from the fruiting body of $L$. edodes. The virus was tentatively named L. edodes mycovirus HKB (LeV). Based on the deduced RNA-dependent RNA polymerase (RdRp) sequence, phylogenetic analysis of LeV was conducted. Because no virion particles associated with the dsRNA were observed by electron microscopic observation, atomic force microscopy (AFM) observation was chosen for achieving molecular imaging of the virus.

Results: The 11,282-bp genome of LeV was obtained. The genome encoded two open reading frames (ORFs). ORF1 coded for a hypothetical protein and ORF2 for a putative RdRp, respectively. In addition, a region coding for a NUDIX domain was present in ORF1. There was a 62-bp intergenic region between ORF1 and RdRp. Similarity with coat protein of mycoviruses was not found within the whole sequence. Based on phylogenetic analysis of the putative RdRp sequence, LeV grouped into a clade with dsRNA found in the basidiomycetes Phlebiopsis gigantea and Helicobasidium mompa. The clade was placed apart from the Totiviridae and Chrysoviridae families. As suggested from the genome sequence, AFM revealed that the structure of LeV was linear unencapsidated dsRNA.

Conclusions: The results suggest that LeV represents a novel family of mycoviruses, found thus far only among the basidiomycetes.

Keywords: Mycovirus, dsRNA, AFM, Lentinula edodes, Mushroom, NUDIX domain

\section{Background}

In the 1970s, viruses that infect the cultivated mushroom Lentinula edodes, or shiitake, were extensively studied in Japan [1-3], and three morphologically distinct viruses were detected by electron microscopy [1,3]. However, unlike La France disease of the white button mushroom $[4,5]$, mycoviruses have not been associated with shiitake diseases because these mycoviruses have commonly been found in healthy fruiting bodies [1,3]. In the USA, dsRNAs have also been observed in shiitake strains, but these appeared to be latent [6]. In the 1970s, shiitake cultivation was performed by inoculating mycelium spawn on oak logs; however, this labor-intensive method was

Correspondence: ymagae@ffpri.affrc.go.jp

Department of Applied Microbiology, Forestry and Forest Products Research Institute, Tsukuba, Ibaraki 305-8687, Japan gradually replaced by indoor cultivation using sawdust substrate supplemented with rice bran. Currently in Japan, about $75,016 \mathrm{t}$ ( $82 \%$ of all shiitake) are produced indoors annually using bag cultures with a sawdust-based substrate [7]. In a bag culture, the shiitake mycelium is fully grown in the substrate until brown pigment is produced outside and the substrate becomes stiff. Complete browning of the exterior surface of the substrate is an important marker that normal fruiting bodies will develop in the following stage of cultivation. However, abnormal symptoms are occasionally observed in bag cultures, such as the growth of white or fluffy mycelia on the surface of substrate, inadequate or imperfect substrate browning [8], and malformations of the fruiting body. These symptoms often result in serious economic losses. Whether or not these abnormalities are associated with 
mycovirus is unknown. As a first step toward addressing that question, 46 shiitake isolates belonging to $11 \mathrm{com}-$ mercial strains were examined for mycovirus infections [8]. As a result, dsRNA was found in two isolates; one showed imperfect browning and the other was asymptomatic. Agarose gel analysis showed that the isolate with imperfect browning contained several dsRNAs, but the asymptomatic isolate contained only a single dsRNA. In this study, the single dsRNA was tentatively designated as Lentinula edodes mycovirus HKB (LeV) and was sequenced.

\section{Methods \\ dsRNA isolation}

Three fruiting bodies were disrupted in $60 \mathrm{ml}$ of $0.1 \mathrm{M}$ phosphate buffer, and the virus fraction was precipitated with $10 \%$ PEG 8000 and $0.15 \mathrm{M} \mathrm{NaCl}$, as described previously [9]. The PEG precipitate was suspended in TES (10 mM Tris- $\mathrm{HCl}, 1 \mathrm{mM}$ EDTA, $0.15 \mathrm{M} \mathrm{NaCl}, \mathrm{pH}$ 7.0), and total RNA was isolated using the QIAmp Viral RNA Mini Kit (Qiagen) according to the manufacturer's instructions. Then dsRNA was isolated from the viral RNA by DNase I (Promega) digestion for $30 \mathrm{~min}$ at $37^{\circ} \mathrm{C}$, followed by $\mathrm{S} 1$ nuclease (TaKaRa) digestion. The resulting dsRNA was concentrated in nuclease-free water by filtration through Ultrafree $0.5100 \mathrm{~K}$ centrifugal filters (Millipore) several times to remove degraded nucleic acids and salts. Finally, dsRNA was purified with the RNeasy Mini Elute Cleanup Kit (Qiagen).

\section{cDNA library construction and sequencing of dsRNA}

The purified dsRNA served as a template for cDNA synthesis by random priming with the PrimeScript $1^{\text {st }}$ strand cDNA Synthesis Kit (TaKaRa) according to the standard protocol, except that the denaturing condition was changed from $65^{\circ} \mathrm{C}, 5 \mathrm{~min}$ to $98^{\circ} \mathrm{C}, 1 \mathrm{~min}$. The resulting cDNAs were electrophoresed in an agarose gel, and cDNAs sized 1.5-2.0 kb were extracted. The cDNAs were blunt-ended with T4 DNA polymerase, ligated into pUC118/HincII/BAP (TaKaRa), and transformed into E. coli $\mathrm{DH} 10 \mathrm{~B}$ cells by electroporation (Gene Pulser, BioRad). The resulting cloned DNA was sequenced with the BigDye Terminator v.3.1 Cycle Sequencing Kit (Applied Biosystems) with M13 forward and reverse primers. A contiguous region (contig) was assembled with Sequencher ${ }^{\mathrm{TM}} 4.6$ (Gene Codes Corp).

\section{AFM microscopic observation}

The PEG precipitate was suspended in $500 \mu \mathrm{l}$ of TE and filtered through a $0.2-\mu \mathrm{m}$ filter (Millipore), and $1 \mu \mathrm{l}$ of the filtrate was diluted with $50 \mu \mathrm{l} \mathrm{TE}+10 \mathrm{mM} \mathrm{MgCl}_{2}$. The sample was observed using atomic force microscopy (AFM) as previously described [10]. A total of $10 \mu \mathrm{l}$ of the RNA solution was dropped onto freshly cleaved muscovite mica $(1 \times 1 \mathrm{~cm})$, which after standing for several minutes was washed with distilled water. The sample was dried under a stream of nitrogen. Observations were performed on a MFP-3D (Asylum Research) in the tapping mode in air, using a silicon cantilever OMCL-AC240TS (Olympus). Fields of $2 \mu \mathrm{m} \times 2 \mu \mathrm{m}$ were scanned at a frequency of $<2 \mathrm{~Hz}$. To confirm that the AFM image observed was RNA, AFM imaging was also performed with PEG precipitate after RNaseA digestion. The length of the RNA molecule was measured using software developed by the Research Institute of Biomolecule Metrology Co., Ltd. (Japanese patent P2000-230823A).

\section{Phylogenetic analysis}

An unrooted polygenetic tree was constructed with sequences retrieved by a PSI-BLAST [11] search (Table 1) using the neighbor-joining method with a bootstrap of 1000. The sequence identity was below $40 \%$; thus, we used the Multiple Alignment using Fast Fourier Transform (MAFFT) program L9INS-I http://mafft.cbrc.jp/alignment/server/[12] for making the multiple alignments and constructing the phylogenetic tree. Sequences with bootstrap values above $70 \%$ were included in the tree and visualized on the web http://www.genome.jp/tools/mafft/

\section{Results and discussion}

\section{Genetic analysis}

A cDNA library was constructed from dsRNA purified from the fruiting body of Lentinula edodes strain HKB. An 11,282-bp cDNA contig containing two open reading frames (ORFs) was obtained (deposited under Accession No.AB429556) (Figure 1). ORF1 encoded a 218,428-Da protein composed of 1,975 amino acids, containing the conserved motif of a NUDIX domain (between 319aa and 451aa) (pfam00293, NUDIX, 1.56 $\mathrm{e}^{-04}$ ) [21]. Viral coding NUDIX domain has been found only in Poxviruses [22]. LeV, as well as Phlebiopsis gigantea mycovirus dsRNA 1 is the first mycovirus described, that codes for NUDIX domain. ORF2 encoded a 162,240-Da protein composed of 1426 amino acids, containing the conserved motif of RNA-dependent RNA polymerase (RdRp) (pfam02123, RDRP_4, 4.48e ${ }^{-22}$ ). The deduced amino acid sequence of ORF1 showed significant similarity $\left(3 \mathrm{e}^{-83}\right)$ to hypothetical protein PgV-1_gp1 of Phlebiopsis gigantea mycovirus dsRNA 1 [13]. The deduced amino acid sequence of ORF2 showed similarity with members of Totivirus [23] and Chrysovirus [24]. The family Totiviridae includes all the viruses of fungi and protozoa that have virions and a single-component dsRNA genome. The family Chrysovirus includes dsRNA viruses that infect fungi or plants and have four genome components in isometric virions. Because LeV contained a single 
Table 1 RdRp sequences of viruses included in the phylogenetic tree

\begin{tabular}{llllll}
\hline Virus & Accession no. & E-value & Identity & Similarity & References \\
\hline Lentinula edodes mycovirus HKB LeVHKB & BAJ21197 & & & & This study \\
\hline Phlebiopsis gigantea mycovirus dsRNA1 PgV1 & CAJ34333 & $4 e^{-150}$ & $383 / 1197(32 \%)$ & $580 / 1197(48 \%)$ & {$[13]$} \\
\hline Helicobasidium mompa V670 L2-dsRNA virus HmV670 & AB275288 & $7 e^{-33}$ & $26 / 65(40 \%)$ & $40 / 65(62 \%)$ & unpublished \\
\hline Helminthosporium victoriae 145S virus HVV145S & AAM68953 & $1 e^{-15}$ & $89 / 328(27 \%)$ & $141 / 328(43 \%)$ & unpublished \\
\hline Verticillium chrysogenum virus VcV & ADG21213 & $1 e^{-14}$ & $99 / 406(24 \%)$ & $172 / 406(42 \%)$ & unpublished \\
\hline Cryphonectria nitschkei chrysovirus 1 CnCV1 & ACT79257 & $9 e^{-14}$ & $83 / 318(26 \%)$ & $136 / 318(43 \%)$ & {$[14]$} \\
\hline Penicillium chrysogenum virus PcV & AAM95601 & $6 e^{-12}$ & $109 / 455(24 \%)$ & $173 / 455(38 \%)$ & {$[15]$} \\
\hline Anthurium mosaic-associated virus AmV & ACU11563 & $5 e^{-11}$ & $67 / 227(30 \%)$ & $101 / 227(45 \%)$ & unpublished \\
\hline Grapevine associated chrysovirus-1 GaCV1 & ADO60926 & $5 e^{-09}$ & $86 / 371(23 \%)$ & $138 / 371(37 \%)$ & {$[16]$} \\
\hline Aspergillus fumigatus chrysovirus AfCV & CAX48749 & $4 e^{-08}$ & $102 / 455(22 \%)$ & $174 / 455(38 \%)$ & {$[17]$} \\
\hline Circulifer tenellus virus 1 CiTV1 & ADK12924 & $5 e^{-07}$ & $82 / 327(25 \%)$ & $135 / 327(41 \%)$ & {$[18]$} \\
\hline Spissistilus festinus virus 1 SpFV1 & ADK12922 & $1 e^{-06}$ & $84 / 338(25 \%)$ & $139 / 338(41 \%)$ & {$[18]$} \\
\hline Saccharomyces cerevisiae virus L-A ScVLA & AAA50508 & $2 e^{-05}$ & $58 / 230(25 \%)$ & $100 / 230(43 \%)$ & {$[19]$} \\
\hline Sphaeropsis sapinea RNA virus 1 SsRV1 & AAD11601 & $1 e^{-03}$ & $48 / 202(24 \%)$ & $81 / 202(41 \%)$ & {$[20]$} \\
\hline
\end{tabular}

E-values, identity, and similarity values were obtained from PSI-BLAST searches of the deduced amino acid data of RdRp sequences

Viruses that showed bootstrap values above $70 \%$ were included in the phylogenetic tree

component dsRNA genome, it could be classified as a member of Totivirus [23]. But unlike Totivirus, there was no coding region for a coat protein within the LeV genome.

\section{AFM microscopic observation}

No virion or vesicle particles were detected by electron microscopy observation of the PEG precipitate of LeV. Purification of the virus by sucrose density-gradient ultracentrifugation was unsuccessful. When the PEG precipitate was directly digested with RNase, the viral dsRNA could no longer be detected by agarose gel electrophoresis (data not shown). These experimental data suggested that the virus did not form a virion and therefore was vulnerable to excess purification. Because the method is nondestructive, AFM was chosen for further observation [25]. The PEG precipitate was suspended in TE and directly observed under AFM after being filtered through a $0.2-\mathrm{mm}$ filter (Millipore). Numerous linear particles were observed (Figure 2A). The structure (Figure $2 \mathrm{~B}$ ) was very similar to the AFM images of dsRNA observed by Abels et al. and Vilfan et al. [26,27]. To confirm that these structures were RNA, PEG precipitate after RNase digestion was also observed by AFM (Figure

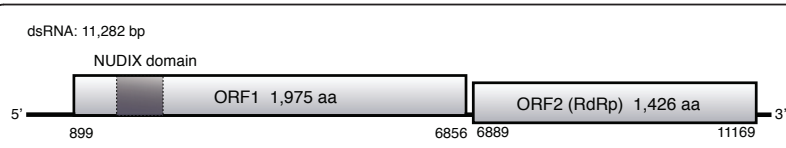

Figure 1 Diagrammatic representation of genome organization of LeV. The dsRNA of LeV encodes two ORFs. ORF1 is an unknown protein and has a region with high similarity with the NUDIX domain. ORF2 encodes the RNA-dependent RNA polymerase (RdRp).
3B). After the RNase digestion, the linear materials were no longer present. Thus, LeV was revealed as a linear dsRNA. The length of the dsRNA was 3,539 nm (Figure $3 \mathrm{~A}$ ), and its molecular weight was estimated (based on 1 $\mu \mathrm{m}=\sim 3 \mathrm{~kb}$ dsRNA [27]) to be $11.8 \mathrm{~kb}$. The estimated size was very close to that of the sequenced dsRNA (11,282 bp).

\section{Phylogenetic analysis}

In the current classification of viruses, unencapsidated mycoviruses are placed in either the Hypoviridae [28,29] or Endornaviridae [30,31] families. However, the putative $\mathrm{RdRp}$ sequence of LeV showed no similarity to the RdRp sequences of Hypovirus or Endornavirus. An unrooted polygenetic tree was constructed with sequences retrieved by a PSI-BLAST [11] search (Table 1) using the neighbor-joining method with a bootstrap of 1000. Sequences with bootstrap values above $70 \%$ were included in the tree (Figure 4 ). This analysis grouped LeV with Phlebiopsis gigantea mycovirus dsRNA1 (E value; 4e $\mathrm{e}^{-150}$ ) (CAJ34333) and Helicobasidium mompa V670 L2-dsRNA virus (translated in this study from AB275288) (E value; $7 \mathrm{e}^{-33}$ ) in a clade independent of Totiviridae and Chrysoviridae (Figure 4). Both $P$. gigantea and $H$. mompa are basidiomycetes. No virion particles associated with $P$. gigantea mycovirus dsRNA have been described [13]. Currently, whether $H$. mompa dsRNA forms virions or not is unknown. If $H$. mompa dsRNA was also unencapsidated, this would suggest that there is a novel family of mycoviruses so far found only in the basidiomycetes, having a monopartite dsRNA genome but do not package into virions. 


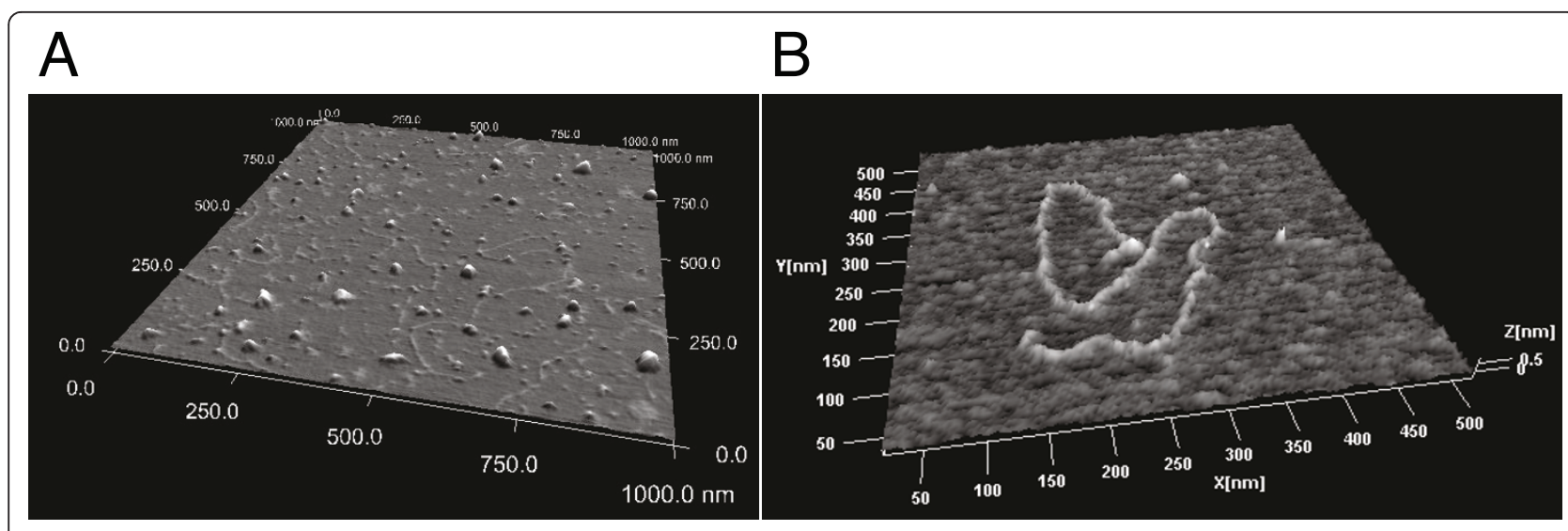

Figure 2 AFM images of a LeV. AFM images of PEG precipitate. (A) LeVs appear as numerous linear nucleic acids. (B) Image of a single LeV dsRNA.

\section{Hypothesis of unencapsidated virus in the}

\section{basidiomycetes}

L. edodes is a white-rot basidiomycete and P. gigantea is also a basidiomycete that causes white rot in conifer logs and stumps [32,33]. Often, P. gigantea is isolated from bark beetle, as is Lentinula boryana, a fungus belonging to the same family as L. edodes [34]. Virion structure is necessary for a virus to infect and exit from the host cell and gain a greater probability of propagation. Because bark beetles feed on basidiomycete fungi [34], the evolution of unencapsidated virus in white-rot basidiomycetes may have been achieved through their association with wood-feeding insects. Because their host can be efficiently transferred to new environments by bark beetles, the coat protein would no longer be necessary for virus propagation. Additionally, the conserved amino acids of putative RdRp molecules of unencapsidated viruses isolated from plant-feeding insects, such as the alfalfa hopper and beet leafhopper [18], are significantly similar to LeV (Figure 4) (Table 1). This fact also supports the hypothesis that unencapsidated species of mycovirus present in the basidiomycetes might be closely associated with insects.

\section{Conclusions}

dsRNA found in a commercial strain of Lentinula edodes (shiitake) (designated as L. edodes mycovirus HKB; LeV) was sequenced. The 11.8-kb genome contained two ORFs. ORF1 coded for a hypothetical protein containing a NUDIX domain. Previously, viral NUDIX domain was found only in Poxviruses. LeV is the only mycovirus that codes NUDIX domain. ORF2 coded for RdRp with high similarity with Totivirus and Chrysovirus. The genome did not code for a coat protein, and AFM observation revealed $\mathrm{LeV}$ to be unencapsidated linear dsRNA. The results show that LeV is a novel

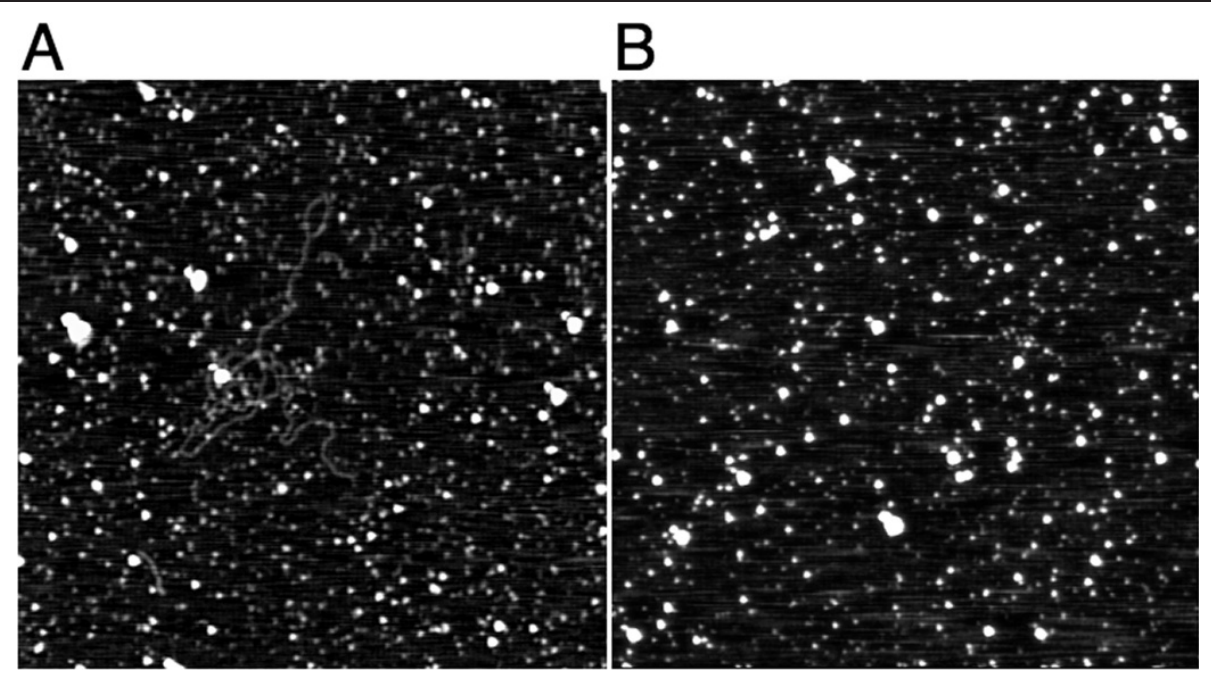

Figure 3 AFM image of RNase-digested LeV. (A) $2 \mu \mathrm{m} \times 2 \mu \mathrm{m}$ AFM image of LeV. Length: 3,539 nm. (B) After exposure to RNaseA digestion. 


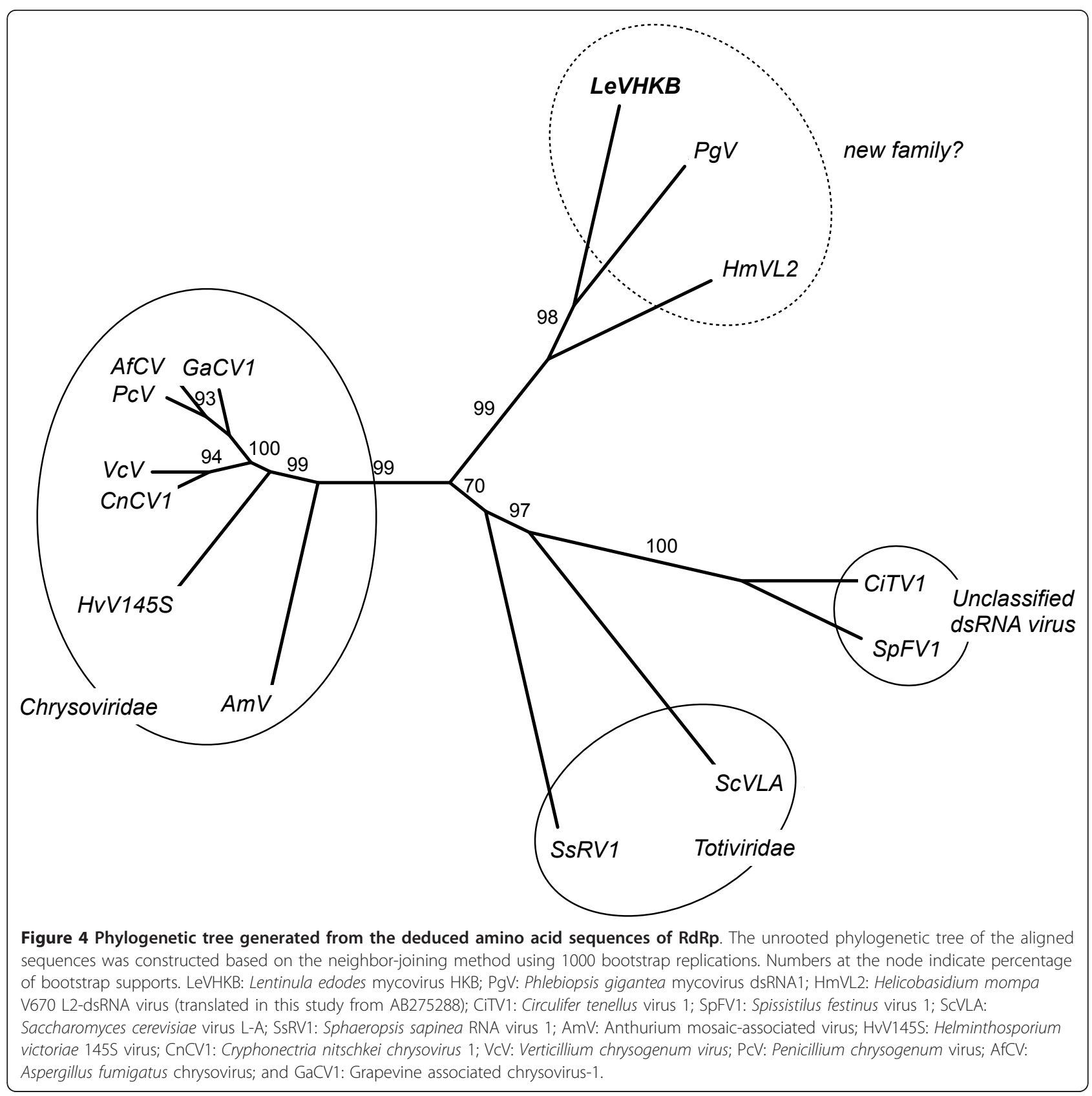

mycovirus with a monopartite dsRNA genome that is closely related to Totivirus, but that it does not form a virion particle and might represent a new class of mycovirus.

\section{Acknowledgements}

I would like to thank China Ohta, Katsumasa Eda, and Sumio Ayusawa of Hokken Co., Ltd. for providing fruiting bodies of strain HKB and all the collaboration during the project granted by the Agriculture, Forestry and Fisheries Research Council of Japan. I would also like to thank Dr. Junji Magae for valuable suggestions. Construction of cDNA libraries and sequencing was performed by TaKaRa Bio Inc. AFM was performed at the
Research Institute of Biomolecule Metrology Co., Ltd., (RIBM) Enokido, Tsukuba, Ibaraki, 305-0853, Japan.

\section{Competing interests}

The author declares that they have no competing interests.

Received: 1 June 2011 Accepted: 6 March 2012 Published: 6 March 2012

\section{References}

1. Ushiyama R, Hashioka Y: Viruses associated with Hymenomycetes I Filamentous virus-like particles in the cells of a fruit body of shiitake, Lentinus edode (Berk) SING. Rept Tottori Mycol Inst 1973, 10:797-805.

2. Ushiyama N, Nakai Y, Ikegami M: Evidence for double-stranded RNA from polyhedral virus-like particles in Lentinus edodes (BERK) Sing. Virology 1977, 77:880-883. 
3. Mori K, Kuida K, Hosokawa D, Takehara M: Virus-like particle in several mushrooms. Mushroom Sci: Proceedings of the Tenth Internation/ Congress on the Science and Cultivation of Edible Fungi 1978, 10:773-787.

4. Sinden JW, Hauser E: Report of two new mushroom diseases. Mushroom Sci 1950, 1:96.

5. Fletcher JT, Gaze RH: La France disease. In In Mushroom Pest and Disease Control. Edited by: Fletcher JT, Gaze RH. London: Manson Publishing Ltd; 2008:114-118.

6. Rytter $\lrcorner$, Royse DJ, Romaine CP: Incidence and diversity of doublestranded RNA in Lentinula edodes. Mycologia 1991, 83:506-510.

7. Statics of Forestry Agency, Ministry of Agriculture, Forestry and Fisheries. [http://www.rinya.maff.go.jp/j/tokuyou/tokusan/1.html], (in Japanese).

8. Ohta C, Taguchi T, Takahashi S, Ohtsuka K, Eda K, Ayusawa S, Magae Y: Detection of double stranded RNA elements in cultivated Lentinula edodes (in Japanese). Mushroom Sci Biotechnol 2008, 16:155-158.

9. Magae $Y$, Sunagawa M: Characterization of a mycovirus associated with the brown discoloration of edible mushroom, Flammulina velutipes. Virol J 2010, 7:342.

10. Umemura K, Nogami F, Okada T, Kuroda R: AFM characterization of single strand-specific endonuclease activity on linear DNA. Nucleic Acid Res 2000, 28:E39.

11. Altschul SF, Madden TL, Schaffer AA, Zhang J, Zhang Z, Miller W, Lipman DJ: Gapped BLAST and PSI-BLAST: a new generation of protein database search programs. Nucleic Acid Res 1997, 25:3389-3402.

12. Katoh $\mathrm{K}$, Kuma $\mathrm{K}$, Toh $\mathrm{H}$, Miyata M: MAFFT version 5: improvement in accuracy of multiple sequence alignment. Nucleic Acid Res 2005 33:511-518.

13. Kozlakidis Z, Hacker CV, Bradley D, Jamal A, Phoon X, Webber J, Brasier CM, Buck KW, Coutts RH: Molecular characterisation of two novel doublestranded RNA elements from Phlebiopsis gigantea. Virus Genes 2009, 39:132-136.

14. Kim JM, Kim JA, Park JA, Park SM, Cha BJ, Yang MS, Kim DH: Molecular diversity of chrysoviruses in Korean isolates of a new fungal species, Cryphonectria nitschkei. J Microbiol 2009, 47:441-447.

15. Caston JR, Ghabrial SA, Jiang D, Rivas G, Alfonso C, Roca R, Luque D, Carrascosa JL: Three-dimensional structure of Penicillium chrysogenus virus: a double-stranded RNA virus with a genuine $T=1$ capsid. $J \mathrm{Mol}$ Biol 2003, 331:417-431.

16. Rwahnih AM, Daubert S, Urbez-Torres JR, Cordero F, Rowhani A: Deep sequencing evidence from single grapevine plants reveals a virome dominated by mycoviruses. Arch Virol 2011, 156:397-403.

17. Jamal A, Bignell EM, Coutts RH: Complete nucleotide sequences of four dsRNAs associated with a new chrysovirus infecting Aspergillus fumigatus. Virus Res 2010, 153:64-70.

18. Spear A, Sisterson MS, Yokomi R, Stenger DC: Plant-feeding insects harbor double-stranded RNA viruses encoding a novel proline-alanine rich protein and a polymerase distantly related to that of fungal viruses. Virology 2010, 404:304-311.

19. Icho T, Wickner RB: The double-stranded RNA genome of yeast virus L-A encodes its own putative RNA polymerase by fusing two open reading frames. J Biol Chem 1989, 264:6716-6723.

20. Preisig $\mathrm{O}$, Wingfield $\mathrm{BD}$, Wingfield $\mathrm{MJ}$ : Coinfection of a fungal pathogen by two distinct double-stranded RNA viruses. Virology 1998, 252:399-406.

21. Parrish S, Resch $W$, Moss B: Vaccinia virus D10 protein has mRNA decapping activity, providing a mechanism for control of host and viral gene expression. Proc Natl Acad Sci USA 2007, 104:2139-2144.

22. Parrish S, Moss B: Characterization of a second vaccinia virus mRNAdecapping enzyme conserved in poxviruses. J Virol 2007, 81:12973-12978.

23. Wickner RB, Wang CC: Patterson JL: Totiviridae. In In Virus Taxonomy 8th Report of the ICTV. Edited by: Fauquet CM, Mayo MA, Maniloff J, Desselberger U, Ball LA. Amsterdam: Elsevier; 2005:571-580.

24. Ghabrial SA, Buck KW, Hillman BI, Martelli GP, Milne RG: Chrysoviridae. In In Virus Taxonomy 8th Report of the ICTV. Edited by: Fauquet CM, Mayo MA, Maniloff J, Desselberger U, Ball LA. Amsterdam: Elsevier; 2005:581-590.

25. Kuznetsov YG, McPherson A: Atomic force microscopy in imaging of viruses and virus-infected cells. Microbiol Mol Biol Rev 2011, 75:268-285.

26. Abels JA, Moreno-Herrero F, van der Heijden T, Dekker C, Dekker NH: Single-molecule measurements of the persistence length of doublestranded RNA. Biophys J 2005, 88:2737-2744.
27. Vilfan ID, Kamping W, van den Hout M, Candelli A: An RNA toolbox for single-molecule force spectroscopy studies. Nucleic Acid Res 2007, 35:6625-6639.

28. Nuss DL: Hypovirulence: mycoviruses at the fungal-plant interface. Nat Rev Microbiol 2005, 8:632-642.

29. Nuss DL, Hillman Bl, Rigling D, Suzuki N: Hypoviridae. In In Virus Taxonomy 8th Report of the ICTV. Edited by: Fauquet CM, Mayo MA, Maniloff J, Desselberger U, Ball LA. Amsterdam: Elsevier; 2005:597-601.

30. Gibbs MJ, Pfeiffer P, Fukuhara T: Endornavirus. In In Virus Taxonomy 8th Report of the ICTV Edited by: Fauquet CM, Mayo MA, Maniloff J, Desselberger U, Ball LA 2005, 605:603.

31. Fukuhara T, Moriyama H: Endornaviruses. In In Encyclopedia of Virology. Edited by: Mahy BWJ, Van Regenmortel MHV. Oxford: Elsevier; 2008:109-116.

32. Behrendt CJ, Blanchette RA: Biological processing of pine logs for pulp and paper production with Phlebiopsis gigantea. Appl Environ Microbiol 1997, 63:1995-2000.

33. Cram M: Phlebiopsis (=Phanerochaete, =Peniophora, =Phlebia, =Peniophora) gigantea (Basidiomycetes: Corticiaceae). In Biological Control: A Guide to Natural Enemies in North America Edited by: Shelton AM 2007 [http://www.biocontrol.entomology.cornell.edu/pathogens/phlebiopsis. html]

34. Hsiau PTW, Harrington TC: Phylogenetics and adaptations of basidiomycetous fungi fed upon by bark beetles (Coleoptera; Scolytidae). Symbiosis 2003, 34:111-131.

doi:10.1186/1743-422X-9-60

Cite this article as: Magae: Molecular characterization of a novel mycovirus in the cultivated mushroom, Lentinula edodes. Virology Journal 2012 9:60.

\section{Submit your next manuscript to BioMed Central and take full advantage of:}

- Convenient online submission

- Thorough peer review

- No space constraints or color figure charges

- Immediate publication on acceptance

- Inclusion in PubMed, CAS, Scopus and Google Scholar

- Research which is freely available for redistribution

Submit your manuscript at www.biomedcentral.com/submit
C) Biomed Central 